\title{
Matt Morgan: Treating a VIP patient
}

\author{
Matt Morgan intensive care consultant \\ University Hospital of Wales
}

When the UK prime minister returned to Downing Street just two weeks after leaving hospital, some people questioned whether he had really needed to be treated in the intensive care unit (ICU) in the first place.

Without speculating on Boris Johnson's individual case or the amazing work of the staff who treated him at St Thomas' Hospital, the uncomfortable truth is that most hospitals have "VIP policies" to admit presidents, politicians, or even celebrities to isolation rooms in the ICU, even when they may not medically need it. However, this is designed to protect not the "high value" individuals themselves but rather the care system and other patients around them. And, bizarrely, this policy may cause unintended harm to the VIPs having so called special treatment.

For a hospital to best care for patients it needs a tangled web of people, equipment, departments, and systems to function together. As soon as-for example-a president or a Love Island celebrity arrives on a ward, the delicate interplay between these components can quickly go wrong. The car parks become crowded with journalists, whispered corridor conversations between health workers are overheard, medical record security can become compromised, and open access to wards has to be restricted.

Cumulatively, such lapses in hospital protocol can have a negative impact on the care of patients who are far removed from the VIP. Admitting people to an already restricted and controlled area of the hospital, such as the ICU, can help mitigate harms to others.

\section{Changes in decision making}

However, giving any patient the "VIP treatment" may come with unintended consequences. A decade ago, my dad was taken into hospital with abdominal pain and vomiting. A twisted bowel was promptly diagnosed, it was treated with simple measures, and he was soon ready to return home. As I carried his bags out from the hospital ward I saw an old medical school acquaintance of mine who happened to be caring for my dad.

This chance meeting led to subtle changes in the decision making of the team, and soon my dad had a new urgent scan planned. That investigation, which was probably not needed, revealed a more serious problem requiring a major operation. Shocked at the dramatic change in plan, my dad declined the operation, and 10 years later he has remained entirely healthy. And so, while VIPs are sometimes treated in areas such as the ICU in order to protect the wider hospital system, as well as other patients and staff-rather than for the VIPs themselves to benefit from so called special treatment-there is a risk that this could result in harm rather than health.

bmj.com Careers: Do you know who I am? Treating a VIP patient (BMJ 2016;353:i2857, doi:10.1136/bmj.i2857)

Competing interests: I have read and understood BMJ policy on declaration of interests and declare that I have no competing interests.

Provenance and peer review: Commissioned; not externally peer reviewed. Matt Morgan, honorary senior research fellow at Cardiff University, consultant in intensive care medicine, research and development lead in critical care at University Hospital of Wales, and an editor of BMJ OnExamination.

Patient consent obtained.

Published by the BMJ Publishing Group Limited. For permission to use (where not already granted under a licence) please go to http://group.bmj.com/group/rights-licensing/ permissions 